\title{
AS FUNCIONALIDADES DOS SERVIÇOS NA ATUAL CONFIGURAÇÃO MUNDIAL DA PRODUÇÃO E SEUS IMPACTOS PARA O ESTUDO DA INDÚSTRIA
}

Fernanda Vilhena ${ }^{1}$

\begin{abstract}
Palavras-chave: serviços, manufatura, interdependência, estudo, Indústria
\end{abstract}
Key-words: services, manufacturing, interdependence, Industry study

\section{Classificação JEL: L60, L80, C80}

Resumo: o trabalho aborda o aumento da importância dos serviços nas últimas décadas, a partir da internacionalização da fragmentação da produção, destacando três funcionalidades assumidas pelos mesmos: o de conectores dos blocos produtivos dispersos geograficamente, o de participantes ativos das etapas de produção (offshoring de serviços) e o de agregadores de valor às manufaturas. Um impacto relevante desses papeis é a crescente interdependência entre manufatura e serviços, o que pode ser comprovado em evidências empíricas de diversos países e sob a ótica do emprego, do produto e do comércio internacional segundo o valor adicionado. Essa tendência gera questionamentos para o estudo da Indústria, sendo que o trabalho destaca três: i) a necessidade de uma revisão da literatura de desindustrialização; ii) oportunidade de discussão sobre os fatores e políticas geradoras de desenvolvimento para os países; iii) limitações do estudo empírico, ainda calcado em estatísticas baseadas na divisão entre manufatura e serviços.

\begin{abstract}
: the paper discuss the increasing importance of services in recent decades, starting in the period of internationalization of fragmentation production, highlighting three features used by service sectors: the connectors of production blocks geographically dispersed, the active actors of the production steps (offshoring services) and to incorporate value to manufacturing. A significant impact of these roles is the increasing interdependence between manufacturing and services, which can be showed on empirical evidence from different countries and from the perspective of employment, output and trade in value added. This trend raises questions for the study of the industry, especially in three main issues: i) the need for a review of deindustrialization literature s; ii) discussion opportunity on the factors and development generating policies for countries; iii) the empirical study also underpinned by statistics based on the division between manufacturing and service.
\end{abstract}

\footnotetext{
${ }^{1}$ Doutoranda do Programa de Pós-Graduação em Economia do Instituto de Economia da Universidade Federal do Rio de Janeiro (PPGE-IE/UFRJ) e analista licenciada do Instituto Brasileiro de Geografia e Estatística (IBGE).
} 


\section{1 - Introdução:}

Desde o início dos anos 1980, a organização da produção ganhou progressivamente um desenho mais complexo, no qual as diversas etapas que compõem o processo produtivo, desde sua concepção até os serviços de pós-venda, são quebradas e dispersas geograficamente entre países, no que se denomina internacionalização da fragmentação da produção. Ao mesmo tempo, observam-se profundas transformações na organização da Indústria, com queda na produção e emprego das manufaturas e crescimento da importância dos serviços nas principais economias mundiais. Nesse contexto, esse trabalho pretende discutir as funcionalidades dos serviços na atual organização mundial da produção e sua relação com as modificações na natureza e escopo das manufaturas, que passam a ser mais intensivas em ocupações de serviços e a utilizar mais serviços como input.

A primeira funcionalidade dos serviços é a de conectores dos estágios de produção dispersos geograficamente, e embora caracterize uma participação mais passiva no processo de produção, essa função é bastante relevante, por viabilizar a fragmentação da produção.

O segundo papel dos serviços na atual organização da produção mundial tem uma característica mais ativa, na medida que remete à existência de estágios de produção, constituídos de tarefas tipicamente de serviços, que também são fragmentados e dispersos geograficamente. Assim, os serviços não apenas são conectores dos segmentos de produção, como são parte integrante dos mesmos.

Ainda, na terceira função, os serviços são agregadores de valor aos produtos, dado que no processo produtivo recente, a manufatura propriamente dita tem contribuído com uma agregação de valor relativamente menor do que as etapas de serviços ( $\mathrm{P} \& \mathrm{D}$, vendas, marketing, serviços de pós-venda). Como consequência, ocorre um movimento de incorporação de atividades de serviços por empresas tradicionalmente manufatureiras e uma oferta crescente de produtos compostos, através da incorporação dos serviços aos bens e à sua venda como um pacote único.

Uma importante consequência dessas três novas funcionalidades é o aumento da interdependência entre indústria e serviços, na medida que o percentual de atividades de serviços necessário para o processo produtivo, ou complementares a ele, tem aumentado. Tomando como exemplo um bem manufatureiro, o automóvel, observa-se que seu processo de produção envolve diversas atividades de serviços ( $\mathrm{P} \& \mathrm{D}$, design, gestão de $\mathrm{RH}$, pesquisa de mercado), assim como a venda é geralmente realizada em um pacote que inclui os serviços de financiamento, que pode ser ofertado diretamente pela empresa produtora ou indiretamente, via subcontratação. Esse incremento na complexidade da interação entre manufatura e serviços tem importantes impactos para o estudo da Indústria.

Assim, após esta parte introdutória, este trabalho apresenta as três funcionalidades dos serviços, através de uma discussão teórica e da apresentação de evidências empíricas de sua ocorrência. Em seguida, discute-se a relação das funções com a ligação manufatura-serviços, realçando os indicadores que mostram tendência de incremento na interdependência entre ambas. Por fim, apresentam-se considerações finais em duas dimensões: uma conclusiva, que discutirá os impactos que essa maior interação tem sobre o estudo da indústria, sobretudo na questão da mensuração estatística; e uma propositiva acerca de abordagens analíticas alternativas.

\section{2 - Funcionalidades dos serviços na atual organização mundial da produção}

Desde o início dos anos 1980, a organização da produção ganhou progressivamente um desenho mais complexo, no qual as diversas etapas que compõem o processo produtivo, desde sua concepção até os serviços de pós-venda, são quebradas e dispersas geograficamente entre países, no que se denomina internacionalização da fragmentação da produção. Nessa atual configuração da produção mundial, os serviços aumentaram sua presença ${ }^{2}$ e assumiram uma função mais relevante, exercendo papeis que

\footnotetext{
${ }^{2}$ Nas últimas décadas, ocorreram mudanças significativas na estrutura produtiva global, incluindo o aumento da relevância dos serviços em termos mundiais, o que pode ser comprovado por um incremento de sua participação no PIB mundial:
} 
podem ser organizados em três grandes blocos (Figura 1). A primeira funcionalidade é a dos serviços como conectores dos Blocos Produtivos (BPs) dispersos geograficamente, viabilizando a fragmentação da produção. A segunda se caracteriza pelos serviços como parte integrante dos BPs (input), configurando um outro tipo de offshoring, além das atividades manufatureiras tradicionalmente engajadas nesse processo. Por fim, o terceiro papel é o dos serviços como agregadores de valor às manufaturas (output) através da servitização, com maior engajamento das firmas manufatureiras em atividades típicas de serviços ou até mesmo a geração de produtos compostos.

Figura 1 - As funcionalidades do setor serviços na atual organização mundial da produção

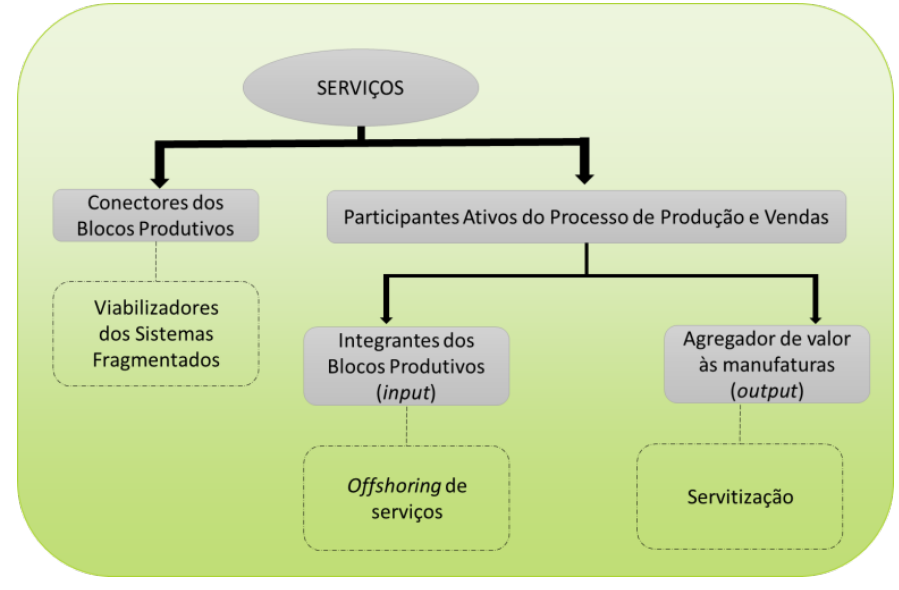

Fonte: elaboração própria.

Embora o primeiro papel seja o mais discutido devido à sua importância na viabilização da fragmentação da produção, o segundo e o terceiro, que tratam dos serviços como participantes ativos dos processos de produção e vendas, também tem relevante função na organização da produção mundial recente.

\section{1 - Serviços como conectores dos blocos de produção}

Para compreender o primeiro papel, é útil recorrer ao enfoque da fragmentação da produção introduzido pioneiramente por Jones e Kierzkowski (1990, 2001), baseado na diferenciação de um modelo de produção integrada de um sistema onde os componentes do processo de produção são separados fisicamente, podendo se localizar fora das fronteiras da firma e da fronteira nacional. Para tanto, os autores partiram de dois conceitos-chave: Blocos Produtivos (BPs) e Serviços Conectores (SCs).

Um sistema integrado verticalmente corresponde a um BP único (Figura 2, a), onde todas as etapas do processo produtivo estão concentradas localmente (em uma fábrica), com objetivo de reduzir custos e riscos. Ao contrário, na organização da produção em sistemas fragmentados, o processo produtivo está dividido em BPs dispersos e os SCs exercem o papel de juntá-los, viabilizando a produção. Assim, os distintos BPs componentes dos sistemas fragmentados são as partes do processo produtivo que foram quebradas e separadas fisicamente e podem ocorrer em distintas localidades e/ou firmas, de maneira linear ou simultaneamente, de tal forma que ao fim do processo haverá a junção de todas em uma localidade para a montagem do produto final que será ofertado ao consumidor. A Figura 2 exemplifica diferentes padrões de relação entre os BPs e SCs, desde níveis de interdependência mais simples (b), até

representavam 53\% em 1970 e atingiram 70\% em 2010 (World Bank’s World Development Indicators, 2012). Este incremento é tradicionalmente compreendido como reflexo da mudança dos países avançados para economias de serviços e das melhorias nos métodos e técnicas estatísticas para mensuração dessa atividade. Porém, ele também está relacionado à emergência e intensificação do processo de fragmentação mundial da produção. 
casos em que os BPs ocorram simultaneamente e seus respectivos outputs necessitem de um BP de montagem no estágio final de fabricação (c).

Figura 2 - Tipos de organização do processo produtivo

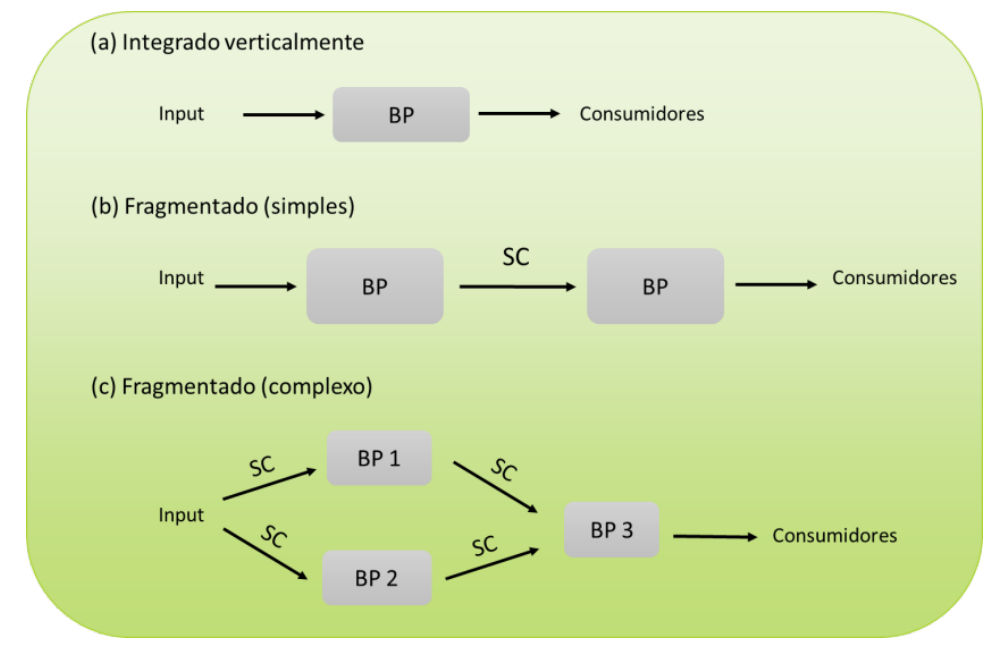

Fonte: Jones e Kierzkowski (1990).

Enquanto em uma produção concentrada em um BP único, os serviços exercem a função de coordenar as atividades internas ao bloco e de conectar produção e consumo através da distribuição e comercialização, na organização da produção em sistemas fragmentados, os SCs tem a função essencial de juntar os BPs espalhados geograficamente, viabilizando a produção (JONES E KIERZKOWSKI, 1990). Essas conexões, que consistem em pacotes de atividades de coordenação, administração, transporte e serviços financeiros, se desenvolvem a partir das demandas de conectividade entre os diversos BPs, sendo mais exigidos quanto maior for a necessidade de utilização conjunta de BPs localizados em distintas regiões.

Portanto, os SCs assumem uma função complexa e vital no processo de fragmentação, determinando a extensão dessa última, na medida em que a decisão de fragmentar é baseada na comparação dos custos dos SCs com os ganhos advindos da melhor localização de determinada planta industrial (BALDWIN, 2013).

Os componentes dos custos dos serviços conectores são classificados em quatro categorias: comércio exterior, investimento, comunicações e coordenação (KIMURA E TAKAHASHI, 2004). A primeira categoria, custos de comércio, remete aos dispêndios de: transporte; às barreiras comerciais (tarifárias e não tarifárias); aos custos de informação (procura de compradores e vendedores, pesquisas sobre preferências de estrangeiros); custos associados ao câmbio (volatilidade e incerteza); custos de legislação e regulatórios; e custos de distribuição local (infra-estrutura).Os componentes dos custos de investimento são sobretudo as políticas comerciais (barreiras diretas e indiretas ao IDE), custos de informação (busca por fornecedores), custos de execução de contratos e custos de legislação e regulatórios, que estão associados com a decisão de fragmentar um BP através da utilização de IDE. A terceira categoria, dos custos de comunicação, está associada aos gastos com telecomunicações (taxas de internet, por exemplo), enquanto a quarta, dos custos de coordenação, mantém relação estreita com os prazos e a incerteza que envolve o processo de coordenar uma série de atividades dispersas até que possa ser possível o envio do produto final.

Assim, essa avaliação de custos marca a importância desse novo papel conector dos serviços nos sistemas fragmentados, e é uma referência para explicar a viabilização e intensificação da fragmentação da produção, sobretudo no nível internacional, a partir do avanço significativo das Tecnologias de 
Informação e Comunicação (TICs), que ampliaram a potencialidade dos SCs realizarem a coordenação entre os BPs.

As inovações das tecnologias de informação (TI) permitiram o auxílio computacional em uma grande variedade de tarefas e processos (processamento de texto, desenho, gerenciamento de estoque, produção). Ainda, as significativas melhorias na qualidade, capacidade e confiabilidade das tecnologias de comunicação (TC) permitiu a digitalização da informação e aumentou as opções disponíveis para sua transmissão a baixos custos, propiciando uma transmissão de informação e de comunicação em longas distâncias rápida, acessível e precisa.

A relação do avanço nas TICs $^{3}$ com a importância dos serviços na viabilização da fragmentação da produção está no fato de que grande parte dos custos de coordenação estão relacionados com o acesso à informação, logo essa revolução tecnológica tornou possível coordenar à distância a complexidade das relações nos múltiplos estágios de produção. Assim, permite que ocorra a quebra dos estágios de produção, a relocalização de trabalho e a reintegração desses fragmentos após a conclusão das tarefas, uma vez que diminuíram os custos de coordenação e monitoramento dos blocos de produção separados por longas distâncias.

Ainda, a disseminação do auxílio computacional nos processos de trabalho permitiu sua codificação e modularização. À medida que mais empresas adotaram essas novas tecnologias, as tarefas puderam ser encapsuladas em módulos padronizados, o que facilitou a movimentação do trabalho, ao reduzir a necessidade de troca de conhecimento tácito e da quantidade de novos investimentos de capital ou formação.

O avanço nas TICs também proporcionou inovações de transporte e logística, que proporcionaram queda significativa nos custos de transporte e transformaram a forma de administração logística do comércio e da produção. Destacam-se o investimento em embarcações e aeronaves de grande porte, que permitem explorar economias de escala, além da possibilidade de embarcar produtos desde sua origem até o destino final em container. Associado a essas inovações, foi importante o crescimento das companhias de logística responsáveis por uma série de serviços de apoio que facilitam os movimentos de mercadorias através das fronteiras.

Assim, esse primeiro papel dos serviços como conectores dos blocos de produção dispersos geograficamente, em conjunto com outros fatores, contribui para que a fragmentação ocorra. A comprovação empírica do avanço dessa forma de organização da produção pode ser feita por dados que mostram incrementos na integração dos países no comércio mundial. Dados da OCDE (2013) mostram, em grande parte dos países, crescimento significativo do conteúdo (valor adicionado) estrangeiro nas exportações e na demanda doméstica final, bem como do percentual de insumos importados incorporados nas exportações.

As primeiras observações empíricas e análises acerca da fragmentação da produção remetiam aos BPs constituídos de tarefas ligadas à manufatura, sendo os serviços eram considerados apenas nesse papel de ligar bilateralmente pares de BPs. No entanto, Jones e Kierzkowski (1990) já destacavam que os serviços também tinham potencialidade para serem usados na exploração de futuras formas de fragmentação e realinhamentos dentro do processo de produção, o que é corroborado por Low (2013), que aponta a importância de considerar outras funcionalidades mais ativas, com participação mais direta na produção e venda.

\section{2 - Serviços como parte integrante dos blocos de produção}

\footnotetext{
${ }^{3}$ Detalhes acerca da relação entre os avanços nas TICs e a viabilização da fragmentação podem ser obtidos nos trabalhos de Baldwin (2013) e Blyde (2014).
} 
A partir dos anos 2000, as indústrias e os atores envolvidos na produção mundial organizada em sistemas fragmentados cresceram exponencialmente, abrangendo não só os bens manufaturados, mas também os serviços, desde call centers e contabilidade até procedimentos médicos e atividades de pesquisa e desenvolvimento (P\&D) das principais empresas transnacionais do mundo. Assim, os serviços passam a ser parte integrante dos BPs e não apenas uma ligação entre eles, o que está relacionado a uma intensificação da sua participação direta, como input, no processo produtivo. Por exemplo, pensando na produção de um automóvel em que o fabricante subcontrata o serviço de logística de um produtor de serviços especializado. Ao mesmo tempo, o carro é formado por partes que são produzidas em outras indústrias e este outro produtor pode também ter comprado os serviços de um especialista. Assim, no final, os serviços são embutidos em ambas as partes que são entregues ao montador final e ao próprio carro.

O caráter de novidade deste papel dos serviços está no fato de que tradicionalmente, os serviços eram considerados como não-transacionáveis ou mais fixos, em termos geográficos, do que a produção de bens tangíveis, sobretudo por sua natureza efêmera e customizada, isto é, por consistirem em atividades não rotineiras que requerem o contato presencial entre produtores e usuários, e não estocáveis, sendo historicamente consumidos no local, enquanto são produzidos. Porém, a partir dos avanços nas TICs, várias etapas dos serviços também puderam ser padronizadas, fragmentadas, codificadas, modularizadas e transportadas entre grandes distâncias de forma mais rápida e barata, o que atribui grande potencial aos serviços para serem produzidos longe de onde serão consumidos.

Atrelado a esse ponto, percebe-se nos anos 2000, um incremento significativo do offshoring de serviços, a partir da transferência, por parte de várias empresas multinacionais, de atividades de codificação de software, call-center, atividades de back-office (folha de pagamento, contabilidade, financeira, pesquisa jurídica) para localidades com baixos salários em uma operação de offshoring, seja instalando filiais ou terceirizando o trabalho para contratantes estrangeiros ou contratantes locais com operação no exterior. ${ }^{4}$

Esses dois primeiros papeis dos serviços, profundamente relacionados com a organização da produção mundial em sistemas fragmentados, se refletem na importância crescente dos mesmos na formação das Cadeias Globais de Valor (CGVs) e no conteúdo do comércio internacional. Em termos empíricos, essa constatação se verifica no indicador de participação das atividades de serviços nas exportações brutas (gráfico 1). É importante ressaltar que esse indicador deve ser analisado em termos de valor adicionado, a fim de evitar os problemas de múltiplas contagens provenientes de bens intermediários e serviços que cruzam diversas vezes as fronteiras para processamentos adicionais ${ }^{5}$.

O resultado da análise do valor adicionado de serviços nas exportações brutas mostra que essa participação varia entre 40 e $70 \%$ entre os países considerados, o que denota a importância dessas atividades no comércio internacional. De forma geral, os países apresentam percentuais superiores para os serviços domésticos, mas vale ressaltar que alguns se destacam pela alta participação (acima de um terço) do conteúdo de serviços estrangeiro nas exportações, refletindo o elevado grau de integração nas cadeias globais ou regionais.

Gráfico 1 - Valor adicionado de serviços contido nas exportações brutas, doméstico e estrangeiro - 2011 (como percentual do total das exportações brutas)

\footnotetext{
${ }^{4}$ Sturgeon (2006) destaca alguns exemplos: bancos como o Citicorp, HSBC e JP Morgan e empresas de tecnologia como a Accenture, Dell, Hewlett-Packard e IBM. O destinatário principal deste novo negócio e investimento foi inicialmente a Índia, mas também houve deslocamento para outros lugares da Ásia, Europa Oriental, Irlanda, Canadá, e do Caribe que foram anteriormente utilizados apenas por um conjunto muito limitado de tarefas de serviços simples.

${ }^{5}$ Por essa razão, foram utilizados dados provenientes da base de dados desenvolvida pela OCDE-WTO, Trade in Value Added (TiVA) Database.
} 


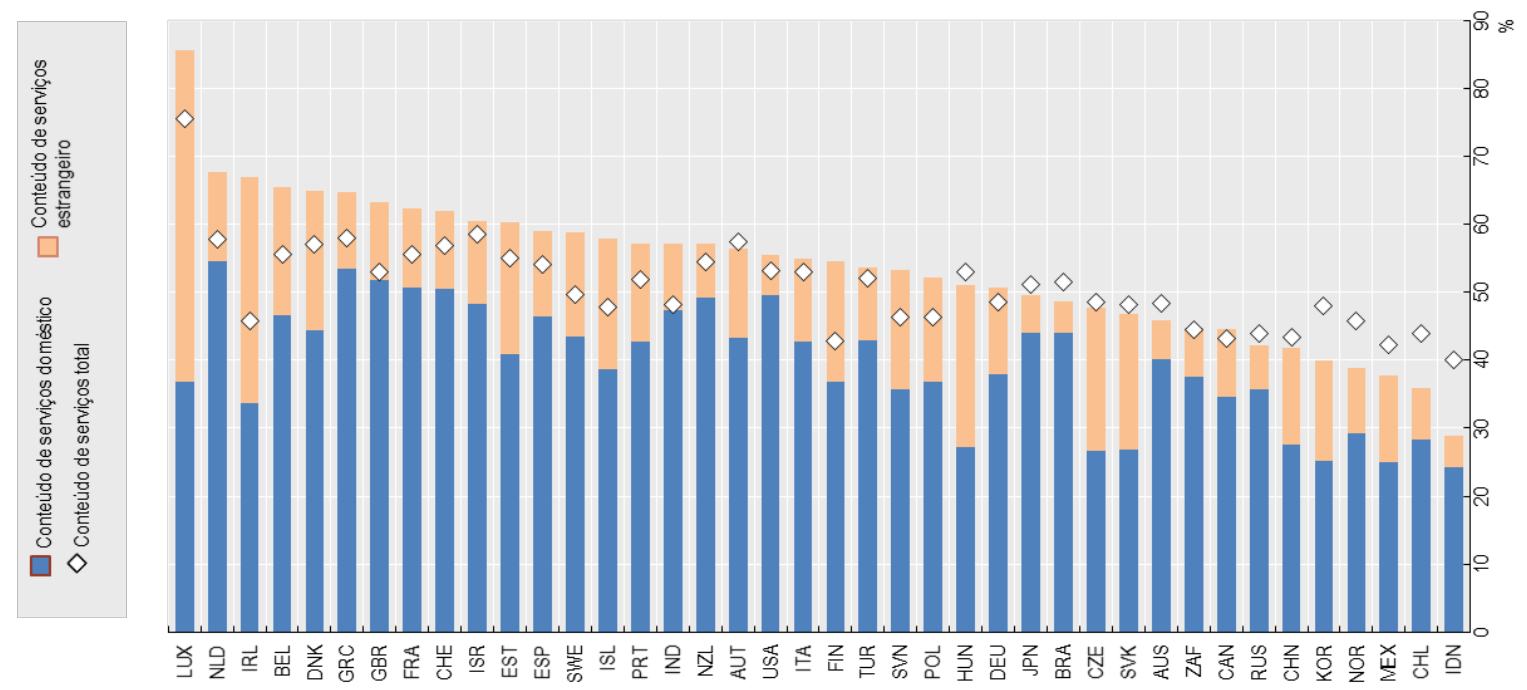

Fonte: OCDE (2015).

\section{3 - Serviços como incorporadores de valor às manufaturas}

A terceira funcionalidade dos serviços remete à sua incorporação à manufatura como forma de agregação de valor ao produto final. Para compreender esse ponto, é útil partir da ideia de que dentro do processo produtivo recente, a manufatura propriamente dita tem contribuído com uma agregação de valor relativamente menor do que as etapas de serviços, tal como estabelece a ótica da curva sorriso (smile curve) ${ }^{6}$, que propõe uma importância relativa maior para as atividades (serviços) de pré e pós 'fabricação em si’ no que tange à incorporação de valor ao produto final.

A interpretação de Baldwin (2013) para a curva sorriso (Figura 3) contextualiza a mesma na atual conformação da estrutura mundial da produção, dividida em estágios de produção, e a contrapõe à curva que vigorava nos anos 1970, mais achatada, o que indica que os diferentes estágios contribuíam de maneira mais equitativa para a geração do VA do produto final.

Figura 3 - Interpretação da curva sorriso original

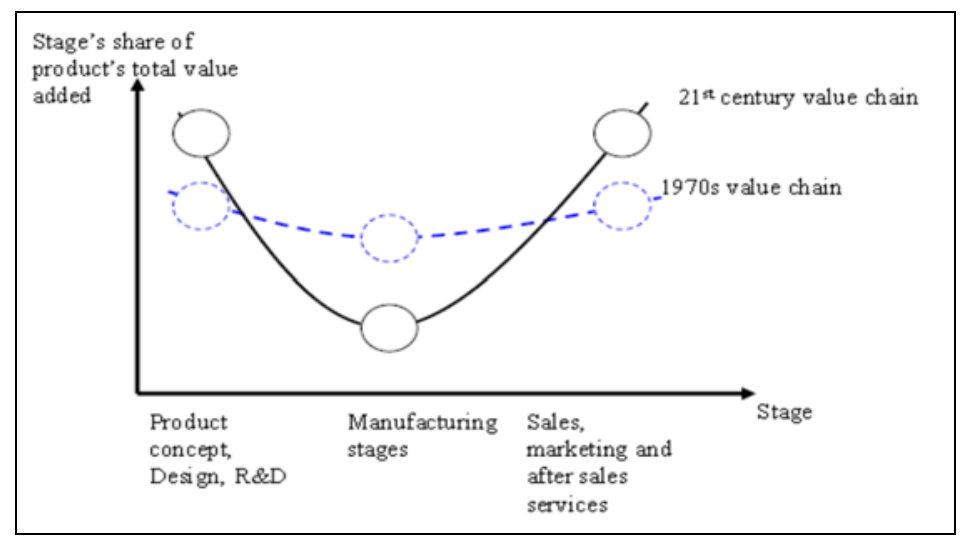

Fonte: Baldwin (2013).

O aprofundamento desta transformação na curva está relacionado com os custos de produção e a transferência de etapas da produção para outros países em busca de menores custos. Assim, se uma etapa

${ }^{6}$ Esta curva foi proposta originalmente por Stan Shih, fundador da Acer. 
da produção tem seus custos reduzidos pelo offshoring e ela é baseada em custos, ela irá gerar menos valor, ainda que a queda nos custos seja repassada para os consumidores. Este efeito pode ser amplificado pelo poder de mercado, pois empresas tendem a transferir a produção apenas dos estágios menos sofisticados da cadeia, permanecendo no controle das etapas que lhe garantem controle através de atributos como diferenciação e marca.

A noção expressa na curva sorriso, de que atividades de serviços contribuem com maior agregação de valor que a manufatura propriamente dita se relaciona ao terceiro papel, de incorporador de valor às manufaturas, que os serviços apresentam dentro da organização do processo produtivo atual.

Essa funcionalidade está associada ao fenômeno da servitização (servitization) ${ }^{7}$, que pode assumir duas formas: pode ser de produto, quando ocorre aumento dos componentes de serviços em um bem, isto é, através da integração entre bens e serviços ou pode ocorrer a servitização de empresa, que seria a transição de uma organização manufatureira para uma mais centrada em serviços (RYU et al, 2012). A servitização de produto está associada à noção de que os serviços, sobretudo os de informação, podem ser embutidos nos bens, isto é, os processos de serviços são materializados e consequentemente incorporados aos bens, gerando produtos compostos (que mesclam bens e serviços em um pacote único).

Embora as empresas manufatureiras vendam serviços há bastante tempo, a maior parte da agregação do valor era avaliada como proveniente dos bens, sendo os serviços apenas um complemento. Além disso, ainda que as manufaturas tradicionalmente necessitem se engajar em alguns serviços (como administrativos) para produzir seus bens, esses têm apenas funcionalidade interna à empresa, o que não permite classificar o evento como servitização.

A constatação empírica da presença crescente da servitização nas empresas manufatureiras não é de fácil verificação e, em grande parte, se baseia em estudos de caso de empresas, que embora informativos, não fornecem uma dimensão clara da escala do fenômeno. Nos últimos anos, alguns trabalhos buscaram essa abordagem quantitativa da servitização aplicada no âmbito de determinado país, como em Crozet e Milet (2014) para a França, em que foi calculado um indicador de intensidade de serviços nas firmas ${ }^{8}$. Por outro lado, buscando uma análise mais abrangente, destaca-se importante estudo $^{9}$ realizado por Neely (2009), que apresenta três tipos de informações: percentual de empresas manufatureiras servitizadas, extensão da servitização por país e tipos de serviços ofertados pelas firmas manufatureiras servitizadas.

Essa última investigação mostra que 30,05\% das empresas manufatureiras analisadas foram classificadas como servitizadas em 2007. Na análise pelo país da firma percebe-se uma diferença significativa, desde os EUA (58,57\%), com maior percentual, até a China, com o menor (0,97\%), como pode ser visualizado na Tabela 1.

Tabela 1 - Percentual de firmas servitizadas, por país - 2007

\footnotetext{
${ }^{7}$ Este termo foi pioneiramente utilizado por Vandermerwe e Rada (1988) para designar os casos de oferta aos clientes de pacotes mais completos de produto, baseados em combinações de bens e serviços. Posteriormente, o ganhou atenção e sua citação na literatura tem sido recorrente, embora com distintas nomenclaturas e definições, tal como expõem Baines et al (2008), Alvizos e Angelis (2010) e Ryu et al (2012).

${ }^{8} \mathrm{O}$ trabalho utiliza uma base de dados coletada pela autoridade fiscal francesa (Bénéfice Réels Normaux - BRE). O indicador de intensidade de serviços nas firmas é calculado pela relação entre vendas de serviços e total da produção vendida (vendas de serviços somadas a de bens, excluído o valor de revenda).

${ }^{9}$ No estudo foi utilizada a base de dados OSIRIS, que contém informações financeiras públicas de firmas de diferentes países, tendo sido analisadas 10.827 empresas manufatureiras (extrativa e transformação) com mais de 100 empregados. A metodologia foi baseada na utilização de um código que identificou na variável 'description and history', que detalha a história e as principais atividades da firma, frases ou palavras que permitissem classificar as empresas em: manufaturas puras, manufaturas servitizadas, e serviços puras.
} 


\begin{tabular}{l|c}
\hline País da empresa & $\begin{array}{c}\text { Percentual de firmas } \\
\text { servitizadas }\end{array}$ \\
\hline EUA & $58.57 \%$ \\
\hline Finlândia & $52.69 \%$ \\
\hline Cingapura & $49.21 \%$ \\
\hline Malásia & $45.64 \%$ \\
\hline Holanda & $40.34 \%$ \\
\hline Bélgica & $37.66 \%$ \\
\hline Noruega & $30.67 \%$ \\
\hline Alemanha & $29.40 \%$ \\
\hline Bermudas & $28.21 \%$ \\
\hline Suíça & $27.74 \%$ \\
\hline Suécia & $27.45 \%$ \\
\hline Taiwan & $26.90 \%$ \\
\hline Ilhas Cayman & $26.76 \%$ \\
\hline Espanha & $25.84 \%$ \\
\hline Grã-Bretanha & $25.49 \%$ \\
\hline Grécia & $24.19 \%$ \\
\hline Austrália & $22.70 \%$ \\
\hline República Tcheca & $21.25 \%$ \\
\hline Dinamarca & $20.59 \%$ \\
\hline Tailândia & $20.09 \%$ \\
\hline França & $18.85 \%$ \\
\hline Indonésia & $15.29 \%$ \\
\hline Áustria & $14.49 \%$ \\
\hline Japão & $11.64 \%$ \\
\hline China & $0.97 \%$ \\
\hline
\end{tabular}

Fonte: Neely (2008).

Em Neely et al (2011), a mesma metodologia é aplicada para o ano de $2011^{10}$, o que permite concluir que não houve uma tendência de mudança significativa em termos de servitização nesse período de seis anos, uma vez que o percentual de firmas servitizadas (30,1\%) se mantém próximo ao observado em 2007. Assim, embora se observe um percentual significativo de servitização, não há uma comprovação empírica disseminada entre as empresas da amostra investigada no sentido de incremento desse percentual, a despeito da discussão acadêmica e de política pública crescente nessa temática.

Na análise temporal (2011 versus 2007) por país, observa-se grandes disparidades, uma vez que alguns deles não apresentaram mudança significativa na taxa, enquanto outros tiveram elevação ou redução da mesma. Merece destaque o caso da China, que apresentou a mudança mais significativa, uma vez que o percentual de firmas chinesas servitizadas saiu de menos de 1\% em 2007 para 19,33\% em 2011. Este grande crescimento da servitização das empresas manufatureiras chinesas é explicado pela intervenção estatal e por uma estratégia deliberada dessas firmas de se moverem para níveis mais altos na cadeia de valor, tal como as manufaturas dos países desenvolvidos.

O estudo também destaca os principais tipos de serviços que foram ofertados pelas empresas classificadas como servitizadas. Nos dois anos em que a metodologia foi aplicada verificou-se, embora em ordenamento diferenciado, que os quatro mais importantes foram: serviços de design e desenvolvimento; sistemas e soluções; varejo e distribuição; e manutenção e suporte.

\section{3 - Ampliação da interdependência entre manufatura e serviços}

\footnotetext{
${ }^{10}$ Foram analisadas 13.775 empresas manufatureiras (extrativa e transformação) com mais de 100 empregados.
} 
As novas funcionalidades dos serviços discutidas acima estão associadas com profundas transformações na organização da Indústria. De forma geral, observam-se queda na produção e emprego das manufaturas em contraposição à maior relevância dos serviços nas principais economias mundiais, ao mesmo tempo em que se modifica a natureza e escopo das manufaturas, que passam a ser mais intensivas em ocupações de serviços e a utilizar mais serviços como input. Realmente, tal como evidenciado na seção anterior, a produção de determinados bens e serviços está amarrada, seja na esfera doméstica ou ao longo de cadeias. Nesse sentido, é importante verificar empiricamente esse incremento da interdependência entre manufatura e serviços e seus impactos para o estudo da Indústria.

A mensuração da interdependência entre serviços e manufatura não é tão facilmente obtida, uma vez que envolve assuntos diversos e complexos, distintos níveis de análise, dificuldade de obtenção de dados comparáveis e necessidade de avaliação criteriosa dos indicadores mais apropriados (PILAT E WÖLFL, 2005). Grande parte dos estudos empíricos dessa temática não são comparáveis, o que prejudica estudos mais precisos e aplicáveis à política pública, por tratarem de distintos assuntos, períodos e por se concentrarem em um ou poucos países.

A fim de fornecer uma visão mais ampla e comparável do fenômeno, importantes indicadores foram calculados por Pilat e Wölfl (2005) e, posteriormente, replicados e ampliados em divulgações do Scoreboard da OCDE ${ }^{11}$. Eles são um indicativo de que nos últimos anos, em vários países, houve um incremento da participação das atividades de serviços necessárias para a produção manufatureira.

O primeiro indicador se fundamenta na composição do emprego nas empresas manufatureiras, através do retrato das ocupações, destacando-se aquelas associadas a serviços ${ }^{12}$. Assim, da análise por país da participação de ocupações relacionadas a serviços nas firmas manufatureiras (Gráfico 2) depreende-se que o intervalo de variação deste indicador está entre $20 \%$ e 50\% no último ano investigado. $\mathrm{Na}$ análise da variação temporal, percebe-se que, com exceção do Japão, todos os países apresentaram incremento no percentual nos dois anos considerados. Portanto, esse indicador é um indicativo de que em vários países, há uma importância crescente dos serviços para a realização da produção manufatureira.

Gráfico 2 - Participação do emprego em ocupações relacionadas a serviços nas firmas manufatureiras- 2000 e 2012 (como percentual do emprego total das manufaturas)

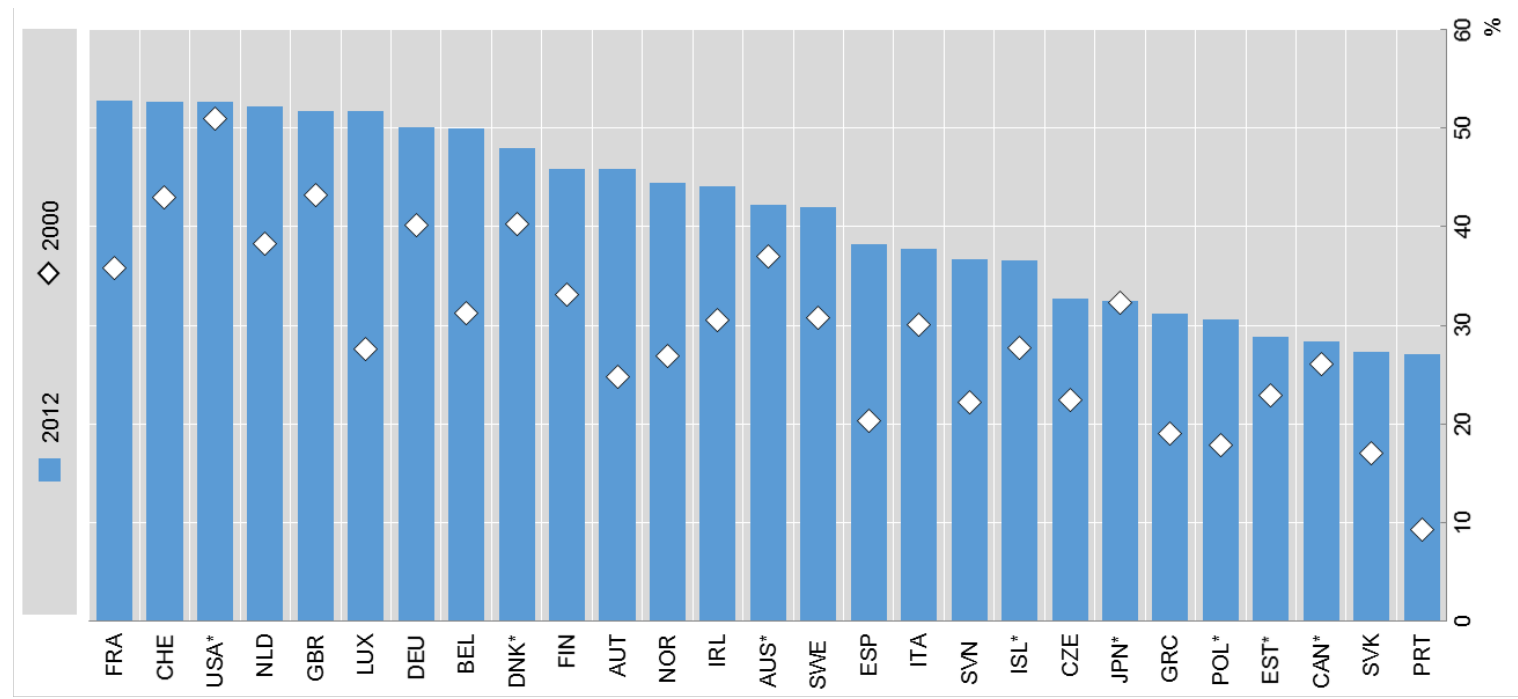

Fonte: elaboração própria a partir de OCDE (2011 e 2013).

(*) O ponto mais antigo da comparação corresponde aos seguintes anos para cada país, respectivamente: USA(2003), DNK(2002), ISL(2002), JPN(2003), POL(2008), EST(2002), TUR(2008). O ponto mais recente da comparação corresponde ao ano de 2008 para os seguintes países: USA, AUS, JPN e CAN.

\footnotetext{
${ }^{11}$ OCDE (2005, 2011, 2013 e 2015).

12 Para o ano de 2002, considerou-se como empresas manufatureiras aquelas classificadas nas divisões 15 a 37 (ISIC Rev.3) e, em 2012, as divisões 10 a 33 (ISIC Rev.4). Considerou-se como atividades relacionadas a serviços, os seguintes grandes grupos 1, 2, 3, 4 e 5 da ISCO-88.
} 
A aplicação de metodologia ${ }^{13}$ semelhante para o caso do Brasil mostra que, em 2014, aproximadamente $27 \%$ das ocupações das firmas manufatureiras estavam relacionadas a serviços, não tendo ocorrido significativas alterações nesse percentual na comparação com os dez anos anteriores. Assim, para esse indicador, não sobressai um resultado expressivo em termos de integração entre manufatura e serviços no país.

O segundo indicador, que está baseado na análise da quantidade de serviços incorporados em uma unidade da demanda final por bens manufaturados ${ }^{14}$, mostra que a contribuição do valor adicionado de serviços necessário para satisfazer a demanda por produtos manufaturados varia entre 10 e 30\%, como é possível visualizar no gráfico 3, o que também sugere uma forte relação entre os dois tipos de atividades. Tomando a variação entre 1995 e 2005, incrementos significativos são observados em alguns países, indicando que em tais localidades ocorre uma mudança na estrutura industrial para produtos manufatureiros mais intensivos em serviços. No Brasil essa relação estava em 18,4\% em 1995 e subiu para 21,3\% em 2005, também demonstrando aumento na relevância dos serviços na produção manufatureira.

Gráfico 3 - Valor Adicionado dos serviços incorporados na produção manufatureira -1995 e 2005 (como percentual do valor adicionado total pelos bens manufaturados na demanda final)

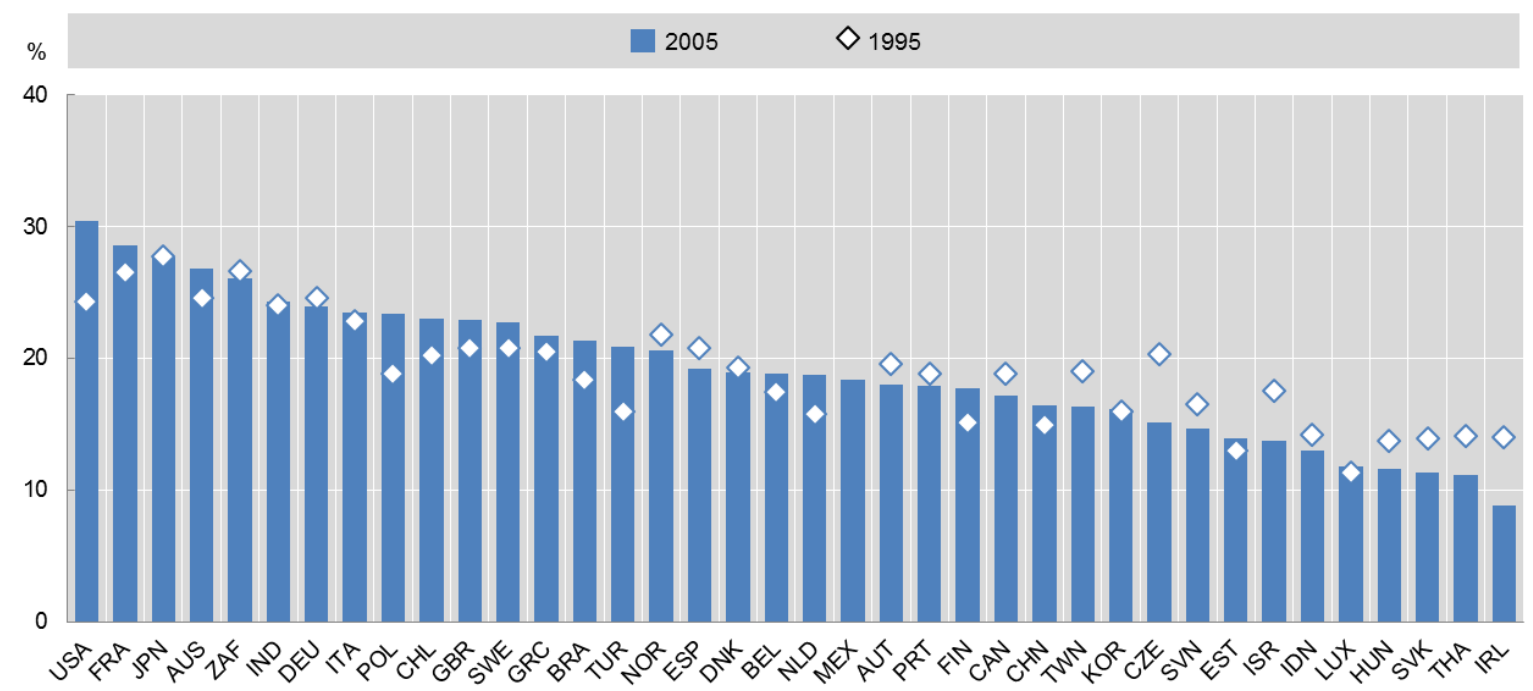

Fonte: OCDE (2011).

O terceiro indicador remete ao conteúdo de serviços contido nas exportações manufatureiras, tomando como referência o valor adicionado, e pode ser analisado sob duas óticas: pela origem (doméstico ou estrangeiro) e pelo tipo de serviço. ${ }^{15}$

Pela participação do valor adicionado de serviços nas exportações manufatureiras observa-se que em 1995 havia uma variação entre os países dentro do intervalo de 20 a 35\%, o que demonstra crescimento significativo em 2011, quando a variação ocorreu entre 30 e $45 \%$. Neste último ano, verificase em vários países uma relevância significativa do conteúdo de serviços estrangeiros, em alguns casos, até superior à participação do conteúdo doméstico, o que demonstra a elevada importância dos mesmos

\footnotetext{
${ }^{13}$ Foram utilizados dados da RAIS. As empresas manufatureiras foram aquelas classificadas nas divisões 10 a 33 (CNAE 2.0) e considerou-se como ocupações relacionadas a serviços as pertencentes aos grupos 1, 2, 3, 4 e 5 da CBO-2002.

${ }^{14}$ Utilizou-se dados compatibilizados pela OCDE das matrizes de insumo-produto nacionais dos países.

${ }^{15}$ Esses indicadores foram calculados a partir da base de dados desenvolvida pela OCDE-WTO, Trade in Value Added (TiVA) Database. Foram considerados como serviços aqueles classificados nas seguintes divisões da ISIC Rev. 3 (International Standard Industrial Classification of all Economic Activities): 50 a 52 - comércio atacadista e varejista; 60 a 63 - transporte e armazenagem; 65 a 67 - intermediação financeira e seguros; 70, 71, 73 e 74 - outros serviços prestados às empresas; 64 e 72 Serviços TIC; e 45, 55 e 75 a 93 - outros serviços.
} 
como fator de integração nas cadeias. No Brasil, observa-se importante crescimento do percentual total, de 26,2\% para 37,7\% entre os dois anos investigados, porém com grande prevalência do conteúdo doméstico.

Gráfico 4 - Valor Adicionado de serviços incorporado nas exportações manufatureiras, doméstico e estrangeiro - 2011 (como percentual do total das exportações manufatureiras)

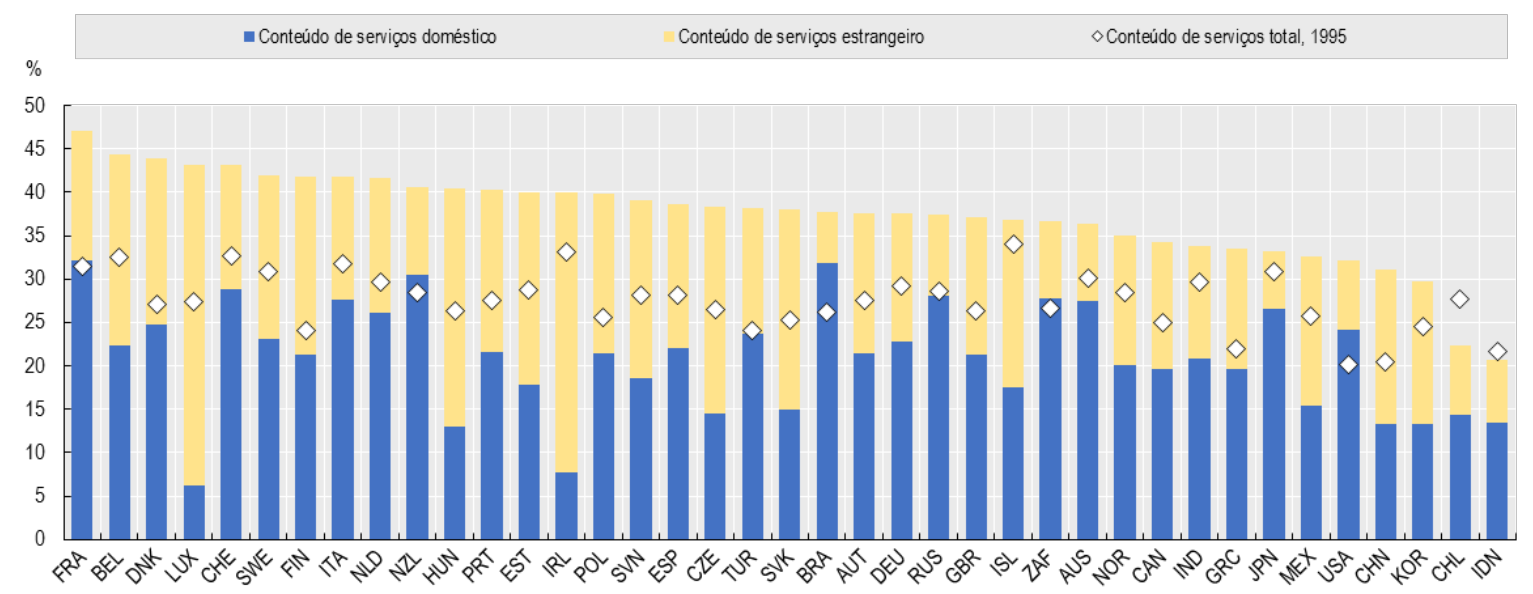

Fonte: OCDE (2015).

A análise deste indicador no ano de 2011, pela ótica do tipo de serviço, mostra que na maior parte dos países, inclusive o Brasil, sobressaem como mais relevantes os setores de comércio atacadista e varejista e o dos outros serviços prestados às empresas (Gráfico 5). Se estes números forem comparados com os de 1995, para a maioria dos países observa-se que a participação do comércio atacadista e varejista e do transporte permanecem relativamente estável, enquanto nos setores de serviços TIC, financeiros e outros serviços prestados às empresas há uma ampliação.

Gráfico 5 - Valor Adicionado de serviços incorporado nas exportações manufatureiras por tipo de serviço - 2011 (como percentual do total das exportações manufatureiras)

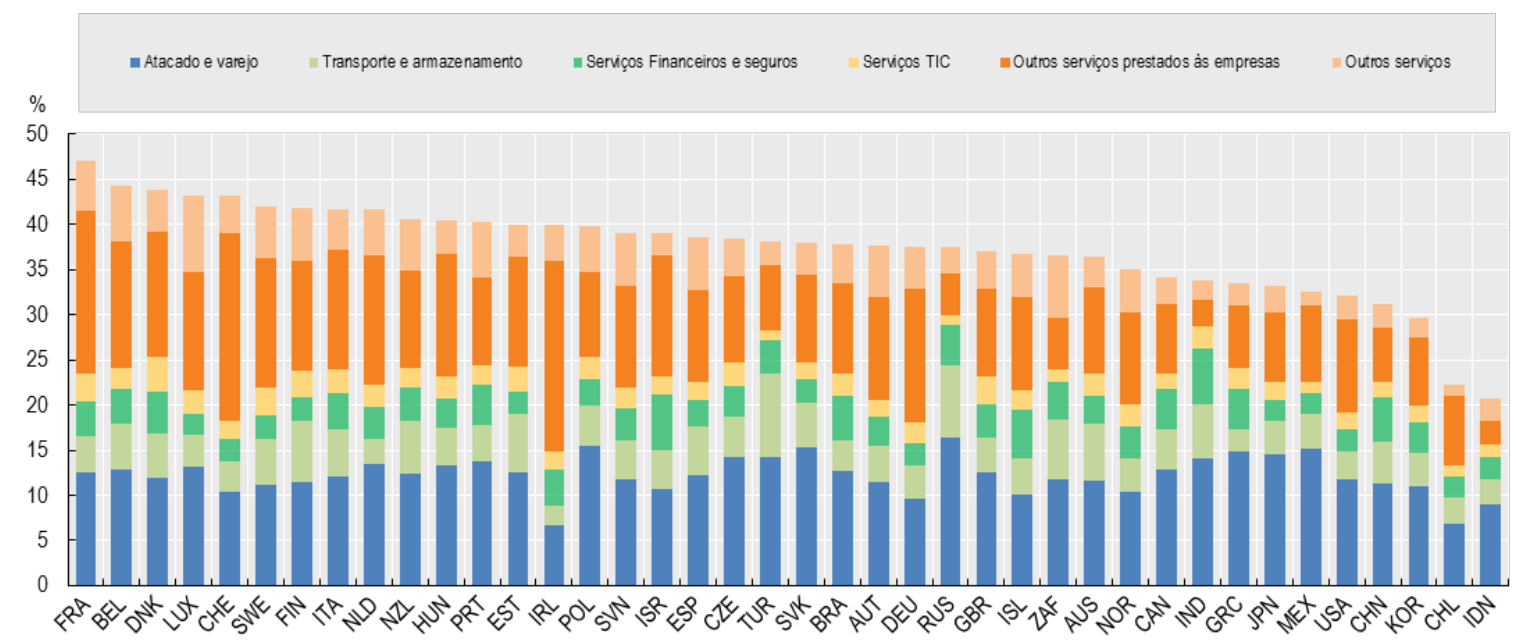

Fonte: OCDE (2015).

Os indicadores analisados nessa seção apresentam evidências empíricas significativas de que é crescente a utilização e importância dos serviços para as manufaturas, o que amplia a interdependência entre ambas atividades e acarreta impactos significativos em termos dos estudos relacionados à Economia Industrial. 


\section{4 - Considerações sobre a relação da crescente interdependência da manufatura e dos serviços para o estudo da Indústria}

Da análise da atual organização da produção mundial - baseada em indicadores compatibilizados de distintas fontes, variáveis e países - evidencia-se uma tendência para a crescente importância dos serviços, que assumem funções relevantes e transformadoras, impactando na forma como as empresas definem seu portfólio de produtos (bens e serviços), inputs, fornecedores, investimentos e localização geográfica. A principal derivação desse cenário é a forte interdependência que se estabelece entre manufatura e serviços e seus impactos significativos para o estudo da Indústria. Nessas considerações, o enfoque será de três pontos: i) a necessidade de uma revisão da literatura de desindustrialização; ii) oportunidade de discussão sobre os fatores e políticas geradoras de desenvolvimento para os países; iii) limitações do estudo empírico, ainda calcado em estatísticas baseadas na divisão entre manufatura e serviços.

A primeira temática abordada nessas considerações é a da desindustrialização. Diversos estudos empíricos ${ }^{16}$ constatam que, nas últimas décadas, a participação do setor manufatureiro declina, tanto em termos de emprego quanto de valor adicionado (VA), em favor dos serviços em vários países, sobretudo os desenvolvidos. Uma vasta literatura discute as causas dessa transferência de importância entre esses dois setores. Para Baumol (1967), seria uma consequência natural do processo de desenvolvimento econômico, considerando as diferenças entre manufatura e serviços no aumento da produtividade no longo prazo. Uma outra explicação se baseia nas preferências dos consumidores, isto é, diferenças de elasticidade-renda da demanda de bens e serviços (KUZNETS, 1957; CHENERY, 1960). Ainda, aparece associada à discussão acerca das estratégias de outsourcing ou offshoring das firmas, isto é, à decisão de localização de etapas da produção dentro ou fora da empresa/país, o que pode acarretar em deslocamentos de emprego e valor adicionado.

Os estudos acerca da desindustrialização se baseiam em sua maioria na realocação de empregados e VA entre indústrias. No entanto, a ampliação da participação dos serviços dentro das empresas manufatureiras, inclusive pela oferta de serviços por parte das mesmas, que acarreta nessa interdependência crescente entre manufatura e serviços, gera um outro tipo de desindustrialização que parece estar sendo camuflada pelas análises tradicionais desse tema.

Isso porque as novas funcionalidades dos serviços, sobretudo a servitização, acarreta em desindustrialização interna ao setor manufatureiro e às empresas manufatureiras, o que é ocultado pelas estatísticas baseadas na classificação por indústria. Em trabalho empírico realizado por Crozet e Milet (2014) são apresentados indícios de que essa desindustrialização oculta é relevante.

Portanto, a possibilidade de que exista uma perda de importação interna à manufatura, que está oculta por não aparecer nas estatísticas tradicionais, tornando o fenômeno da desindustrialização ainda mais intenso, realça a necessidade de construção de uma agenda de trabalho que aprofunde esses estudos, tanto em termos teóricos quanto em relação às medidas (indicadores) adequados para mensurar o fenômeno em sua magnitude.

A segunda linha de discussão que se abre a partir da percepção dessa crescente importância dos serviços na economia mundial, inclusive para o próprio setor manufatureiro, está relacionada às estratégias no que se refere à localização das atividades produtivas (etapas de produção propriamente dita e de serviços) e seus impactos sobre os resultados das empresas e o emprego e o produto de países.

Considerando-se que as combinações possíveis para a decisão de localização geográfica e organizacional da estrutura da produção e de suas partes abrangem o cruzamento de duas dimensões manter dentro de uma única firma ou transferir para outra(s) firma(s) e manter dentro ou fora do país haveria quatro opções estratégicas (Antràs e Helpman, 2004): i) a produção efetuada por empresa de estrutura vertical em único país; ii) alguns estágios da produção podem ser realizados internamente pela firma, porém outros são transferidos para filiais no exterior, através de Investimento Direto Estrangeiro

\footnotetext{
${ }^{16}$ Um destaque é o trabalho de Pilat et al (2006).
} 
(IDE) vertical; iii) partes da produção com terceirização para fornecedores independentes, porém localizados no país de origem; e iv) a produção com terceirização para fornecedores independentes, com quem a firma mantém uma relação de compra de partes ou serviços de suporte através de comércio internacional.

Dessas possibilidades e considerando as novas funcionalidades dos serviços, sobretudo sua relevância para as manufaturas, depreende-se a necessidade de retomar a discussão, porém sob nova perspectiva, de temas diversos da literatura de economia industrial, como por exemplo a discussão sobre especialização produtiva. A opção de um país pela concentração em uma ou poucas etapas de serviços pertencentes ao processo de produção e cuja agregação de valor seja maior que a manufatura propriamente dita traria perdas ou ganhos em termos de emprego, inovação, valor adicionado e renda?

Uma terceira linha de discussão que se abre a partir da constatação de que os limites entre indústria e serviços são mais tênues e essas atividades mutuamente dependentes é a dificuldade crescente de realizar análises empíricas da Indústria. A despeito das restrições permanentes relacionadas à intangibilidade e heterogeneidade das atividades de serviços e dos novos problemas nos indicadores da manufatura, como por exemplo a mensuração do fenômeno da desindustrialização explicitado acima, acrescenta-se a crescente complexidade de estabelecer os limites de separação entre os serviços e a manufatura. As estatísticas tradicionais não estão aptas a transpor esse problema, uma vez que sua estrutura de informação é baseada na classificação da empresa por sua atividade econômica principal, o que em última instância leva à separação analítica entre manufatura e serviços.

Justifica-se, portanto, a necessidade de geração de novos dados e métodos que tenham maior aderência às necessidades analíticas e empíricas dessa nova forma de organização da Indústria. Uma linha de trabalho alternativa que tem se mostrado profícua é a abordagem das Funções Produtivas (FP) ${ }^{17}$, baseada na organização das estatísticas econômicas segundo uma listagem de tarefas.

As FP são todas as atividades ou tarefas específicas que as firmas realizam desde a concepção do produto até os serviços de pós-venda, sendo que podem ser providas internamente ou adquiridas a partir de terceirização para outros estabelecimentos de propriedade da mesma empresa ou pertencentes a empresas juridicamente distintas (STURGEON E GEREFFI, 2008). Este conceito tem como fundamento teórico a noção de 'value activities', desenvolvido pioneiramente por Michael Porter (1985), ao tratar da questão da cadeia de valor. Para o autor, a firma é uma sequência de atividades realizadas para viabilizar seu negócio, sendo essas atividades agregadoras de valor ao produto.

Desde o início dos anos 2000, o conceito de FP tem sido desenvolvido e aplicado com finalidades estatísticas por diversos autores. Nesse sentido, foram propostos distintos agrupamentos dessas atividades exercidas por todas as firmas, com o intuito de formular uma listagem de FP que possa ser utilizada em investigações empíricas.

A listagem de FP é compreendida com um conjunto de categorias genéricas e de fácil compreensão que descrevam as atividades ou tarefas realizadas pelas empresas, independente de sua atividade econômica principal (NIELSEN e STURGEON, 2014). Na estatística tradicional, o produto (bem ou serviço) principal de uma firma determina sua classificação setorial através da utilização de um código de atividade padronizado. Esta organização é a base de contabilização de dados de emprego, produto e os demais que constam de um censo ou pesquisa econômica. Na nova abordagem de FP, este método é complementado pela utilização de uma listagem genérica de funções e os dados a nível de empresa são gerados por essas funções específicas e não para a empresa como um todo.

Na medida que essas FP representam todas essas tarefas, que podem estar separadas fisicamente e serem realizadas dentro ou fora da empresa, bem como na economia nacional ou no exterior, considera-se que o foco central de análise desta abordagem são os estágios de produção, o que resolveria a problemática das estatísticas tradicionais organizadas segundo atividade principal que partem da divisão clássica entre manufatura e serviços.

\footnotetext{
17 Tradução da autora a partir do original em inglês, business functions.
} 
Algumas experiências de aplicação da abordagem de FP já foram realizadas: i) Survey of Innovation \& Business Strategy 2009/2012 (Statistics Canada); ii) Mass Layoff Statistics (BLS); iii) International Sourcing Survey 2007 e 2012 (Eurostat); iv) Offshoring Research Network (2009); e v) National Organizations Survey (2011). Em grande parte, a aplicação da abordagem de FP gera estatísticas diretas sobre as estratégias e os impactos do engajamento das empresas e países nas CGVs, através da realização de novas pesquisas. Isso mostra que há espaço e necessidade de que o método seja aprimorado e tenha sua aplicabilidade expandida.

Em síntese, a relevância das funcionalidades exercidas pelos serviços na atual configuração da produção mundial, que impactou no incremento da interdependência entre manufatura e serviços, bem como na dificuldade de tratar essas duas indústrias separadamente em termos analíticos e, sobretudo, empíricos, implica na necessidade de construção de uma agenda que repense a literatura e as estatísticas disponíveis para o estudo da Indústria.

\section{5 - Referências Bibliográficas}

ALVIZOS, E. e ANGELIS, J. (2010). What is servitization anyway? POMS $21^{\text {st }}$ Annual Conference at Vancouver, Canada. Disponível em: http://dx.doi.org/10.1108/17410380910960984. Acesso em: 19 ago 2015.

BAINES, T.S.; LIGHTFOOT, H.W.; BENEDETTINI, O.; KAY, J.M. (2009). The servitization of manufacturing. Journal of Manufacturing Technology Management, Vol. 20 Iss 5 pp. 547 - 567. Disponível em: http://dx.doi.org/10.1108/17410380910960984. Acesso em: 19 ago 2015.

BALDWIN, R. (2012). Global Supply Chains: Why They Emerged, Why They Matter, and Where They Are Going. The Fung Global Institute Working Paper Series: FGI-2012-1.

BAUMOL, W. J. (1967). Macroeconomics of unbalanced growth: The anatomy of urban crisis. American Economic Review, 57(3):415_426.

BLYDE, J. S. (2014). Synchronized Factories: Latin America and the Caribbean in the Era of Global Value Chains. SpringerOpen.

CHENERY, H. B. (1960). Patterns of industrial growth. The American Economic Review, 50(4):pp. 624_654.

CURZEL, R. (2015). A participação dos serviços nas cadeias globais de valor selecionadas. IPEA: Texto para Discussão n. 2082.

CROZET, M. e MILLET, E. (2014). The servitization of French manufacturing firms. CEPI II Working Paper.

JONES, R. e H. KIERZKOWSKI. (1990) The Role of Services in Production and International Trade: A theoretical framework. In R. Jones and Anne Krueger, The Political Economy of International Tade: Essays in Honor of Rbert E. Baldwin. Oxford: Basil Blackwell.

JONES, R. e H. KIERZKOWSKI. (2001). A Framework for Fragmentation. in S. Arndt and H. Kierzkowski, eds., Fragmentation: New Production Patterns in the World Eonomy, New York: Oxford University Press.

KIMURA, F.; TAKAHASHI, Y. (2004) International Trade and FDI with Fragmentation: the Gravity Model Approach.

KUZNETS, S. (1957). Quantitative aspects of the economic growth of nations: Ii. Industrial distribution of national product and labor force. Economic Development and Cultural Change, 5(4):3_111. 
LOW, P. (2013). The role of services in global value chains. In: ELMS, D.; LOW, P. Global Value Chain in a Changing World. Fung Foundation, Temasek Foundation and World Trade Organization.

NEELY, A. (2009) Exploring the Financial Consequences of the Servitization of Manufacturing. Operations Management Research, 2, 1, pp. 103-118.

NEELY, A.; BENEDETTINI, O.; VISNJIC, I. (2011). The servitization of manufacturing: further evidence.

https://www.researchgate.net/publication/265006912_The_Servitization_of_Manufacturing_Further_Evid ence. Acesso em: 10 mar 2016.

OECD (2005). OECD Science, Technology and Industry Scoreboard 2005. OECD Publishing. http://www.sourceoecd.org/scienceIT/9264010556. Acesso em: 10 mar 2016.

OECD (2011). OECD Science, Technology and Industry Scoreboard 2011. OECD Publishing. http://dx.doi.org/10.1787/sti_scoreboard-2011-en. Acesso em: 10 mar 2016.

OECD (2013). OECD Science, Technology and Industry Scoreboard 2015. OECD Publishing. http://dx.doi.org/10.1787/sti_scoreboard-2013-en. Acesso em: 10 mar 2016.

OECD (2015). OECD Science, Technology and Industry Scoreboard 2015. OECD Publishing. http://dx.doi.org/10.1787/sti_scoreboard-2015-en. Acesso em: 10 mar 2016.

PILAT, D. e WÖLFL, A. (2005). Measuring the Interaction Between Manufacturing and Services. OECD Science, Technology and Industry Working Papers, 2005/05, OECD Publishing. http://dx.doi.org/10.1787/882376471514.

Pilat, D. et al. (2006). The Changing Nature of Manufacturing in OECD Economies. OECD Science, Technology and Industry Working Papers, 2006/09, OECD Publishing. http://dx.doi.org/10.1787/308452426871

RYU, J,; HOSUN, R,; PARK, K,; KIM, H. (2012). A Framework for Servitization of Manufacturing Companies in Mangal, V,; Karmakar, U. (eds.) 2012. The UCLA Anderson Business and Information Technologies (BIT) Project: A Global Study of Business Practice, Singapore: World Scientific Publishing Company.

STURGEON, T. J. (2006). Why we can't measure the economics effects of service offshoring: the data gaps and how to fill them. Services Offshoring Working Group Final Report. MIT, Industrial Performance Center.

VANDERMERWE, S.; RADA, J. (1988). Servitization of Business: Adding Value by Adding Services, in European Management Journal 6(4): 314-324. 